\title{
The method of selecting a foaming agent and its concentration in the production of non- autoclaved hard cellular concrete
}

\author{
Pavel Gorbach ${ }^{1, *}$, Sergey Shcherbin ${ }^{1}$, and Andrei Savenkov ${ }^{1}$ \\ ${ }^{1}$ Angarsk State Technical University, 665835 Angarsk, Tchaikovsky str., 60, Russia
}

\begin{abstract}
The paper considers the approach to the selection of the foaming agent and its concentration in the production of non-autoclaved hard cellular concrete, consisting in measuring the basic physico-chemical properties and determining the critical concentration of micelle formation.
\end{abstract}

\section{Introduction}

Non-autoclaved hard cellular concrete is a promising building stone material obtained by solidifying a mixture of sand, cement, water, and a foaming agent. Therefore, another name for this material is widely used, which is the "foam concrete."

The quality and quantity of the foamer, and, correspondingly, the foam significantly affect the density, strength, thermal conductivity, and other operational properties of the foam concrete. In the Russian market, there is a large number of foaming agents surfactants (SC) of different nature under various trade names, of which the most known are "Alkylbenzenesulfonic acid," “Arecom," "Biopore," "PB-2000," "Penostrom", and "Penta Surfactant 430A." Therefore, manufacturers of foam concrete face the difficulty of choosing the most suitable foaming agent.

Another important problem is how to determine the optimum amount of foaming agent in the composition of the initial mixture. Insufficient amount of foam leads to a reduction in the porosity, density, and thermal conductivity of the material, and the surfactant surplus slows the coagulation of cement particles, increases the hydration time and reduces the strength of the foam concrete [1].

The possibility of using a particular foaming agent in the production of cellular concrete is largely determined by the difference in hydrogen values of cement mortar and surfactant, which should be as small as possible to reduce the negative effect on the properties of the material of the steric effect [2].

In work [3] it is shown that the approach to determining the optimum content of a foaming agent can be constructed by detecting the critical concentration of micelle formation (CCMF), the value of which can be obtained by analyzing and mathematical processing the results of measuring the electrical conductivity, surface tension and refractive index of SC solutions.

Therefore, there is a need for a comprehensive study of surfactants in order to identify

*Corresponding author: pgs@angtu.ru 
the most promising foaming agent for use in the production of non-autoclaved hard cellular concrete and its optimum amount.

The study was conducted in several stages:

1. First, the hydrogen index, electrical conductivity, and surface tension were determined for aqueous solutions of foaming agents of different concentrations.

2. By analyzing and mathematically processing the results of the first stage, the critical concentration of micelle formation for the surfactants being studied was determined.

3. Next, the effect of foaming agents on the strength of a cement matrix was considered. The matrix consisted of a cement stone without aggregate or with a minimum amount of cement.

\section{Materials and methods}

At the initial stage, water solutions of the foaming agents "Alkylbenzenesulfonic acid," "Arecom," "Biopore," "PB-2000," "Penostrom", and "Penta PEA 430A" were prepared with a mass concentration of 0.5 to $5 \%$. As a sealer, the distilled and industrial water was used according to GOST 23732-2011.

To determine the hydrogen index according to GOST 50550-93, a pH-150MI device was used. The electrical conductivity of the solutions was determined using a laboratory conductivity meter ECA-2. The surface tension of the solutions was determined by the Rebinder method with the device BH-5504. The critical micelle concentration for the surfactants studied was determined by analyzing and mathematical processing the results by means of Microsoft Excel.

To indirectly assess the effect of foaming agents on the strength of foam concrete, samples of a cement matrix consisting of a cement stone without aggregate or with a minimum quantity thereof, with the addition of a foaming agent in different amounts, were prepared for 28 days. Samples were made in the form of cubes $(100 \times 100 \times 100 \mathrm{~mm})$ and beams $(40 \times 40 \times 160 \mathrm{~mm})$. To determine the strength, a hydraulic press of the IP-1000 brand was used.

The relative strength of the cement matrix samples was determined by the ratio of the strength of the test samples and the control matrix prepared without adding the surfactants.

\section{Results}

Table 1 presents (in descending order) the results of measuring the $\mathrm{pH}$ for the solutions of the surfactants being tested. Taking into account that the $\mathrm{pH}$ of the cement slurry is in the range from 11 to 13 [4], it can be noted that the foaming agent "Penta Surfactant 430A" has the closest $\mathrm{pH}$ value. Based on the results of the measurements, the foaming agent "Alkylbenzenesulfonic acid" was excluded from the further study due to the unacceptably low $\mathrm{pH}$.

Data on the electrical conductivity of aqueous solutions of surfactants of different concentrations are given in Table 2 and were used to determine the critical concentration of micelle formation. The increase in electrical conductivity of solutions with increasing concentration of foaming agents is due to an increase in the number of charged ions. When the CCMF is achieved, ions and molecules are combined to form charged aggregatesmicelles. Micellization leads to a slowing down of the dynamics of electrical conductivity growth, which makes it possible to determine the CCMF [5]. 
Table 1. Hydrogen index of solutions of foaming agents.

\begin{tabular}{|l|c|c|}
\hline \multirow{2}{*}{\multicolumn{1}{|c|}{ Foaming agemt }} & \multicolumn{2}{|c|}{ Mass concentration, \% } \\
\cline { 2 - 3 } & 2,5 & 5 \\
\hline Penta Surfactant 430A & 10,3 & 10,5 \\
\hline Arekom & 8,7 & 8,8 \\
\hline PB-2000 & 8,4 & 8,6 \\
\hline Penostrom & 7,95 & 8 \\
\hline Biopore & 7,8 & 7,85 \\
\hline Alkylbenzenesulfonic acid & 2,2 & 1,9 \\
\hline
\end{tabular}

Table 2. Electrical conductivity of solutions of foaming agents, $\mu \mathrm{S} / \mathrm{cm}$.

\begin{tabular}{|l|c|c|c|c|c|c|c|c|c|c|c|}
\hline \multirow{2}{*}{$\begin{array}{c}\text { Name of blowing } \\
\text { agent }\end{array}$} & \multicolumn{10}{|c|}{ Mass concentration of foaming agent, \% } \\
\cline { 2 - 14 } & 0 & 0,5 & 1 & 1,5 & 2 & 2,5 & 3 & 3,5 & 4 & 4,5 & 5 \\
\hline Arekom & 2,7 & 600 & 980 & 1320 & 1785 & 2140 & 2520 & 2860 & 3200 & 3550 & 4100 \\
\hline Biopore & 2,7 & 1090 & 2310 & 3280 & 4200 & 5190 & 6000 & 7020 & 7900 & 8870 & 9740 \\
\hline PB-2000 & 2,7 & 460 & 830 & 1180 & 1430 & 1850 & 2160 & 2480 & 2760 & 3020 & 3370 \\
\hline Penostrom & 2,7 & 220 & 410 & 610 & 760 & 980 & 1110 & 1270 & 1440 & 1560 & 1790 \\
\hline $\begin{array}{l}\text { Penta Surfactant } \\
\text { 430A }\end{array}$ & 2,7 & 140 & 250 & 380 & 430 & 520 & 580 & 630 & 720 & 800 & 860 \\
\hline
\end{tabular}

The results of determining the surface tension are given in Table 3 and have also been used to determine the boundaries of the critical micelle concentration. It is obvious that the use of the foaming agents "Penta Surfactant 430A" and "Penostrom" leads to a greater decrease in surface tension, if compared with other surfactants, which contributes to the improvement of the conditions for the formation of micelles [6].

Table 3. Surface tension of surfactant solutions, $\mathrm{mN} / \mathrm{m}$.

\begin{tabular}{|l|c|c|c|c|}
\hline \multirow{2}{*}{ Foaming agent } & \multicolumn{4}{|c|}{ Mass concentration of foaming agent, \% } \\
\cline { 2 - 5 } & 0,5 & 1 & 2 & 4 \\
\hline Biopore & 61,41 & 60,42 & 50,93 & 48,61 \\
\hline PB-2000 & 60,7 & 54,3 & 49,8 & 44,5 \\
\hline Arekom & 57,69 & 52,49 & 46,12 & 34,52 \\
\hline Penta Surfactant 430A & 48,17 & 31,83 & 30,47 & 30,95 \\
\hline Penostrom & 45,7 & 32,7 & 29,22 & 29,07 \\
\hline
\end{tabular}

After analyzing the results obtained and their mathematical processing, a critical micelle concentration was determined for the solutions of the foaming agents under study (Table 4).

It is possible to note the smallest value of CCMF, and, accordingly, the greatest activity of foaming agents "Penta Surfactant 430A" and "PB-2000."

The relative strength of cement matrix samples is shown in Table 5 in descending order. It can be concluded that the properties of the surfactant used significantly affect the strength of the material. At the same time, the highest strength is obtained by the samples obtained with the use of "Penta Surfactant 430A."

Thus, it can be stated that, based on the results of a comprehensive study of six surfactants for the production of foam concrete, the foaming agent "Penta Surfactant 430A" can be recommended in an amount corresponding to a critical micelle concentration of $2.6 \%$. 
Table 4. Critical concentration of micelle formation of solutions of foaming agents.

\begin{tabular}{|l|c|}
\hline \multicolumn{1}{|c|}{ Foaming agent } & CCMF, $\%$ \\
\hline Penostrom & 3,47 \\
\hline Arekom & 3,21 \\
\hline Biopore & 3,16 \\
\hline Penta Surfactant 430A & 2,59 \\
\hline PB-2000 & 2,2 \\
\hline
\end{tabular}

Table 5. Relative strength of samples.

\begin{tabular}{|l|c|}
\hline \multicolumn{1}{|c|}{ Name of blowing agent } & Relative strength of the matrix \\
\hline Penta Surfactant 430A & 0,715 \\
\hline Biopore & 0,614 \\
\hline PB-2000 & 0,504 \\
\hline Penostrom & 0,474 \\
\hline Arekom & 0,359 \\
\hline
\end{tabular}

\section{Discussion}

Many publications have been devoted to the study of the properties of foams and foaming agents [7-12]. But in these works, as a rule, the influence of the foaming agent concentration and the properties of the foam obtained on the properties of the foam concrete cannot be traced. It is noted that one of the reasons restraining the increase in production volumes of non-autoclave foam concrete is the complexity of designing its composition. The current regulatory documents, GOST 25485-89 and SN 277-80, are obsolete and do not meet the modern requirements of the construction materials market. Using the recommendations in them, it is impossible to obtain a foam concrete with the necessary properties.

For this reason, manufacturers of this material cannot achieve high performance characteristics of products (primarily strength) and change them as needed. Therefore, the foam concrete is practically superseded at present from the market of building materials by cellular concrete of autoclave hardening.

It is quite obvious that new approaches and methods are much needed for designing non-autoclaved hardened cellular concrete compositions that allow them to vary their properties over a wide range, depending on the requirements (thermal insulation or structural material) [13-15].

Therefore, the problem of selecting a foaming agent and a reasonable choice of its concentration, as having been discussed in this paper, is relevant for the construction industry.

\section{Conclusion}

In our opinion, the approach used, which is to determine the critical concentration of the micelle formation of foaming agents, may find wide practical application in the short term and, possibly, would become part of the new recommendations for the selecting compounds of the non-autoclaved hardening cellular aerated concrete. 


\section{References}

1. A. P. Merkin, P. R. Taube, The Unstable Miracle. Chemistry, 224 (1983)

2. L. D. Shakhova, Bulletin of BSTU named after V.G. Shukhov, 4, 53-59 (2003)

3. S. A. Shcherbin, P. S. Gorbach, Bulletin of TGASU, 1, 216-219 (2007)

4. V. B. Ratinov, F. M. Ivanov, Chemistry in Construction (Stroyizdat, Moscow, 1977)

5. A. A. Slyusar, K. A. Lakhnov, Bulletin of BSTU named after V.G. Shukhov, 4, 89-95 (2003)

6. D. Panesar, Construction and Building Materials, 44, 575-584 (2013)

7. S. A. Shcherbin, P. S. Gorbach, Bulletin of TGASU, 4, 191-199 (2012)

8. I. A. Semenov, M. A. Pokrovskaya, Theoretical Foundations of Chemical Technology, 1, 97 (2014)

9. V. K. Tikhomirov, Chemistry, 265 (1975)

10. A. I. Rusanov, O. A. Levichev, V. T. Zharov, Chemistry, 184 (1981)

11. D. Bickerman, Pena (Springler-Verlan, New York, 1973)

12. K. R. Lange, Surface-active substances: synthesis, properties, analysis, application (Hardcover, 999)

13. Sh. M. Rakhimbaev, D. V. Tverdokhlebov, V. N. Tarasenko, Rheological properties of foam concrete, prepared using foaming agents "Penostrom" and "Neopor". Porobeton 2005 (Publishing house of BSTU named after V. G. Shukhov, Belgorod, 2005)

14. L. D. Shakhova, E. S. Chernosyotova. Effect of the nature of foaming agents on the stability of foam concrete mixes. Porobeton (Publishing House of BSTU named after V. G. Shukhov, Belgorod, 2005)

15. L. D. Shakhova, Technology of foam concrete. Theory and Practice (ACB Publishing House, Moscow, 2010) 